\title{
BADANIA DOŚWIADCZALNE RAMY PORTALOWEJ DO CELÓW WALIDACJI MODELU MES DOCZOŁOWEGO POŁĄCZENIA BELKI ZE SŁUPEM
}

\begin{abstract}
W artykule przedstawiono wyniki badań czwartego etapu walidacji hierarchicznej modeli MES, wykonanego w celu analizy zdolności do obrotu węzłów stalowych. Program badawczy obejmuje wykonanie testów laboratoryjnych dwóch ram portalowych wykonanych z kształtowników walcowanych oraz porównanie wyników testów z wynikami analiz numerycznych wykonanych metodą elementów skończonych przy użyciu oprogramowania Ansys. Jako kryterium porównawcze przyjęto krzywą odpowiedzi kąta obrotu połączenia rygla ze słupem, którą w teście laboratoryjnym wyznaczono za pomocą zestawu inklinometrów. Dokonano oceny wpływu użebrowania w słupie na zdolność do obrotu węzłów. Układ ramowy bez żeber usztywniających wykonano z kształtowników HEB 260, natomiast układ ramowy z żebrami usztywniającymi wykonano z kształtowników HEA 240. Elementy składowe układów ramowych wykonano ze stali S235 oraz S355. Na elementy złączne zastosowano śruby wysokiej wytrzymałości klasy 10.9 według normy ISO 4014.
\end{abstract}

Słowa kluczowe: zdolność do obrotu, walidacja hierarchiczna, analiza MES, rama portalowa, połączenie słup-belka, rama portalowa, połączenie słup-belka

\section{Wstęp}

Badania doświadczalne węzłów w skali naturalnej, wykonywane na próbkach krzyżowych lub wspornikowych, a nieraz także, jako podzespołów konstrukcji stalowych, były od dawna stosowane do oceny zachowania się węzłów. Koszt i pracochłonność takich badań skłoniły badaczy do opracowania metod oceny analitycznej parametrów węzłów. Podsumowanie wyników tych metod modelowania można znaleźć m.in. w [1], [2], [3]. Wieloletnia współpraca naukowców z całej Europy zaowocowała opracowaniem zunifikowanych norm do

${ }^{1}$ Autor do korespondencji / corresponding author: Krzysztof Ostrowski, MTA Engineering Sp. z o.o., krzysztof.ostrowski@mta-online.net

2 Aleksander Kozłowski, Politechnika Rzeszowska, Wydział Budownictwa, Inżynierii Środowiska i Architektury, kozlowsk@prz.edu.pl 
projektowania obowiązujących we wszystkich krajach Unii Europejskiej, tzw. Eurokodów.

Procedury zwarte w normie [4] pozwalają na ilościową ocenę nośności obliczeniowej oraz sztywności początkowej węzłów, lecz w odniesieniu do ilościowej oceny zdolności do obrotu norma ta nie posiada stosownego odniesienia, co czyni ten obszar analiz, jako celowy z punktu widzenia konieczności dalszego rozwoju.

Rozwój techniki komputerowej, której dynamiczny przyrost notuje się od lat 80 ubiegłego wieku, pozwolił na rozwinięcie metod obliczeniowych wykorzystujących metodę elementów skończonych do poziomu, w którym skomplikowane efekty badanych obiektów mogą zostać obliczone na komputerach typu PC. Wcześniej było to możliwe do wykonania na specjalnie skonstruowanych do tego celu jednostkach, dostępnych tylko w centrach obliczeniowych.

Wyniki uzyskane w metodzie elementów skończonych można uznać za wiarygodne tylko wówczas, jeżeli otrzymuje się rezultaty porównywalne z wynikami badań doświadczalnych i/lub znanych rozwiązań ścisłych. Ocenę dokładności modelu MES wykonuje się w procesie weryfikacji i walidacji, który powinien poprzedzać każdą poważniejszą analizę MES [5]. Proces weryfikacji jest oceną dokładności rozwiązania w modelu obliczeniowym MES w porównaniu ze znanymi rozwiązaniami, np. analitycznymi. W procesie walidacji ocenie poddaje się dokładność obliczeniową symulowanych rozwiązań przez porównanie z wynikami eksperymentalnymi. Walidacja powinna być wykonywana stopniowo, tzn. na poziomie modelu materiałowego, zestawu łączników, podzespołów i fragmentów konstrukcji. Nazywane to jest walidacją hierarchiczną.

Na rys. 1. przedstawiono cztery modele charakterystyk materiałowych, które znajdują zastosowanie w analizach MES [6]. Pierwsze trzy modele (rys. 1a, $1 \mathrm{~b}, 1 \mathrm{c})$ reprezentują podejście konserwatywne i znajdują szerokie zastosowanie w badaniach przemysłowych inżynierii materiałowej.

a)

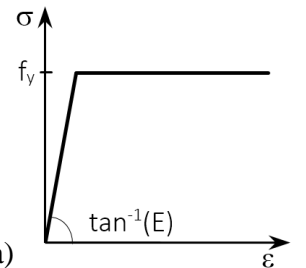

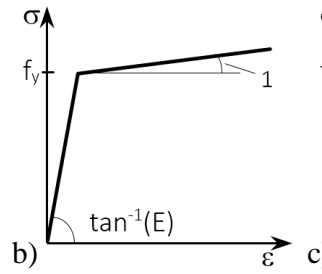

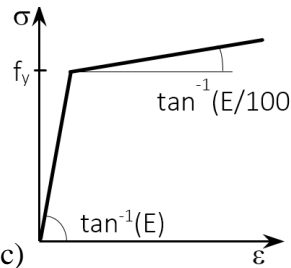

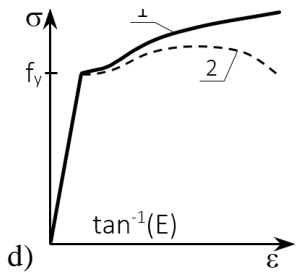

Rys. 1. Modele materiałowe według EN 1993-1-5 [6]: a) model sprężysto-plastyczny bez wzmocnienia; b) model sprężysto-plastyczny z minimalnym wzmocnieniem; c) model sprężysto-plastyczny z liniowym wzmocnieniem; d) model realistyczny uzyskany na podstawie badań laboratoryjnych

Fig. 1. Material models according to EN 1993-1-5 [5]: a) elastic-plastic model without strain hardening; b) ) elastic-plastic model with pseudo strain hardening; c) elastic-plastic with linear strain hardening; d) true stress-strain curve calculated from a technical stress-strain curve 
Charakterystyki materiałowe nieposiadające logarytmicznego odkształcenia są pewnego rodzaju gwarantem niezawodności optymalizowanych obiektów, gdyż w takich przypadkach analiza wykazuje zawsze wcześniejsze osiągnięcie stanu dopuszczalnego naprężenia oraz odkształcenia. Jedyną charakterystyką, która spełnia wymogi wiernego odwzorowania deformacji badanego obiektu jest charakterystyka naprężenie - odkształcenie przedstawiona na rys. 1d. Krzywa oznaczonym numerem 2 jest krzywą inżynierską, opisującą charakterystykę naprężenie-odkształcenie $\mathrm{w}$ odniesieniu do początkowego pola przekroju $\mathrm{A}_{0}$, natomiast krzywa oznaczona numerem 1 przedstawia rozkład naprężenie - odkształcenie odniesione do chwilowych pól przekroju poprzecznego, czyli naprężenia rzeczywiste w odkształconym przekroju A.

Walidację hierarchiczną modeli MES stosowanych w analizie zachowania się węzłów w pełnym zakresie obciążeń, przeprowadzono w czterech etapach: I Etap - badanie materiału próbek stalowych kształtowników oraz materiału śrub, II Etap - rozciąganie śruby w układzie: śruba - podkładka - nakrętka,

III Etap - rozciąganie króćców teowych,

IV Etap - model połączenia belki do słupa obciążonego momentem zginającym badany w układzie ramy portalowej.

a)

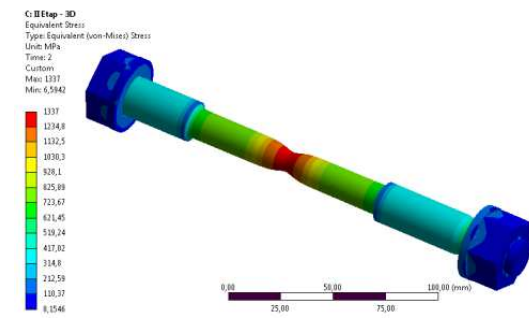

c)

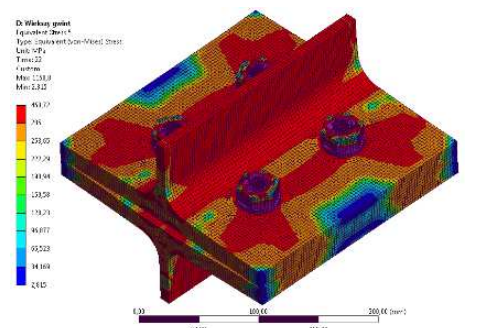

b)

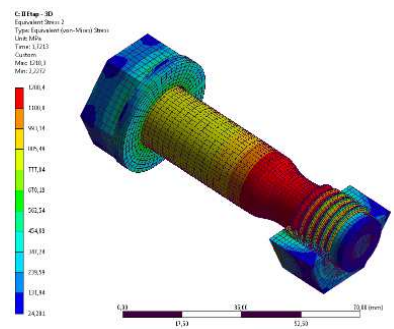

d)

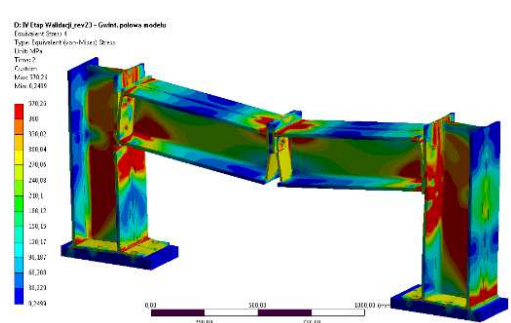

Rys. 2. Wieloetapowa walidacja hierarchiczna modeli MES: a) I etap: badania materiału próbek stalowych i materiału próbek śrub; b) II etap: badanie zestawów łączników w konfiguracji: śrubapodkładka-nakrętka; c) III etap - badanie rozciąganych króćców teowych: d) IV etap: badanie węzłów w konfiguracji ramy portalowej

Fig. 2. Multistage Hierarchical Validation of FEM models: a) I stage: the tests of material of steel samples: b) II stage: the tests of fasteners in the configuration of bolt-washer-nut; c) III stage: the tests of T-stubs; d) IV stage: the joint tests in the configuration of frame 
W pierwszym etapie walidacji wyznacza się charakterystykę materiałową $\sigma-\mathcal{E}$ na podstawie badania materiału próbek stalowych oraz próbek materiału śrub poddanych rozciąganiu (rys. 2a) [2]. Próbki stalowe zostały pozyskane z materiału użytego do wykonania króćców teowych badanych w III etapie walidacji. W celu uzyskania zbieżnych wyników koniecznym jest wykonanie dostrojenia modelu materiałowego zastosowanego w modelu MES. Proces dostrojenia charakterystyk materiałowych uzyskuje się w wyniku modyfikacji krzywej $\sigma-\varepsilon$ do takiej formy, przy której uzyskuje się akceptowalną zgodność wyników z badaniami laboratoryjnymi. Obszar dla którego znana jest charakterystyka naprężenie-odkształcenie wyznacza się ze wzorów (1) oraz (2)

$$
\begin{aligned}
& \sigma_{\text {true }}=\sigma(1+\varepsilon) \\
& \varepsilon_{\text {true }}=\ln (1+\varepsilon)
\end{aligned}
$$

Modyfikacji krzywej dokonuje się tylko w zakresie nieznanego obszaru zachowania materiału, czyli od momentu wytworzenia przewężenia w badanej próbce materiału, dla którego niemożliwym jest określenie relacji naprężenieodkształcenie na podstawie dostępnych w literaturze zależności analitycznych. Wartość maksymalnego naprężenia $\sigma_{u}$ wyznacza się na podstawie wartości siły w rozciąganej próbce przed zerwaniem odniesionym do wartości odkształconego pola powierzchni próbki A po zerwaniu. Wartość maksymalnego odkształcenia $\varepsilon_{u}$ odpowiadająca maksymalnemu naprężeniu $\sigma_{u}$ wyznacza się w sposób iteracyjny zwiększając odkształcenie $\varepsilon_{u}$ do takich wartości, przy której uzyskujemy najlepsze dopasowanie rzeczywistej krzywej odpowiedzi $\sigma$ - $\varepsilon$.

$\mathrm{W}$ drugim etapie walidacji badaniu poddaje się wyizolowane elementy złączne w układzie śruba-podkładka-nakrętka (rys. 2b) [2]. Trzeci etap polega na wyznaczeniu porównawczej charakterystyki $F-\Delta$, która opisuje stan odkształcenia doczołowego połączenia zdefiniowanego w formie rozciąganych króćców teowych. Badanie zostało przeprowadzone dla serii króćców teowych (rys. 2c) wykonanych z kształtowników walcowanych (HEB 240, HEA 240) oraz spawanych z blach. Blachy czołowe króćców teowych wykonane były z blach o grubości $t_{p}$ równej 12 i $20 \mathrm{~mm}$ [2].

W artykule zaprezentowano wyniki czwartego etapu walidacji, w którym analizowany jest model połączenia belki do słupa w układzie ramy portalowej. Miarą walidacji tego etapu jest stopień zbieżności wyników kąta obrotu węzła uzyskanych w analizie MES z otrzymaną z badań laboratoryjnych charakterystyką $F-\phi$. Badania wykonano w Wydziałowym Laboratorium Badania Konstrukcji WBIŚiA Politechniki Rzeszowskiej. We wszystkich etapach walidacji użyto śrub wysokiej wytrzymałości klasy 10.9 według normy ISO 4014 . W badaniu zastosowano elementy wykonane z ze stali S235 oraz S355. 


\section{Opis stanowiska badawczego}

Zakres realizacji czwartego etapu walidacji obejmuje swoim zakresem wykonanie testu laboratoryjnego dwóch ram portalowych. Na rys. 3. przedstawiono zdjęcia stanowiska badawczego. Pierwszy układ ramowy (RH) został zaprojektowany z kształtowników HEA 240. W układzie ramowym RH zastosowano żebra usztywniające w słupie na wysokości dolnej i górnej półki rygla. Słupy zaprojektowano $\mathrm{w}$ rozstawie osiowym $L_{l}=1880 \mathrm{~mm}$, rygle ramy zaprojektowano, jako elementy wspornikowe o wysięgu $L_{2}=800 \mathrm{~mm}$. Pomiędzy elementem RH1-L oraz elementem RH1-P wprowadzono dodatkowy element $\mathrm{w}$ postaci blachy o grubości $t=20 \mathrm{~mm}$ w celu podparcia wałka $(\phi=50 \mathrm{~mm})$ za pomocą którego zostało wprowadzone obciążenie do układu ramowego. Obciążenie układu zostało zrealizowane poprzez wprowadzenie kontrolowanego przemieszczenia w środku rozpiętości ramy z odczytem wartości siły na siłowniku. Rygle zostały połączone ze słupami za pomocą 4 śrub wysokiej wytrzymałości o średnicy M20, klasy 10.9 (ISO 4014). W ramie RH poziomy rozstaw śrub wynosi $w=130 \mathrm{~mm}$, odległość górnej krawędzi półki do osi górnych śrub wynosi $c_{g l}=60 \mathrm{~mm}$. Wszystkie elementy składowe ramy (RH1-L, RH1-P, RH2-L, RH2-P) wykonano ze stali kształtowej S235.
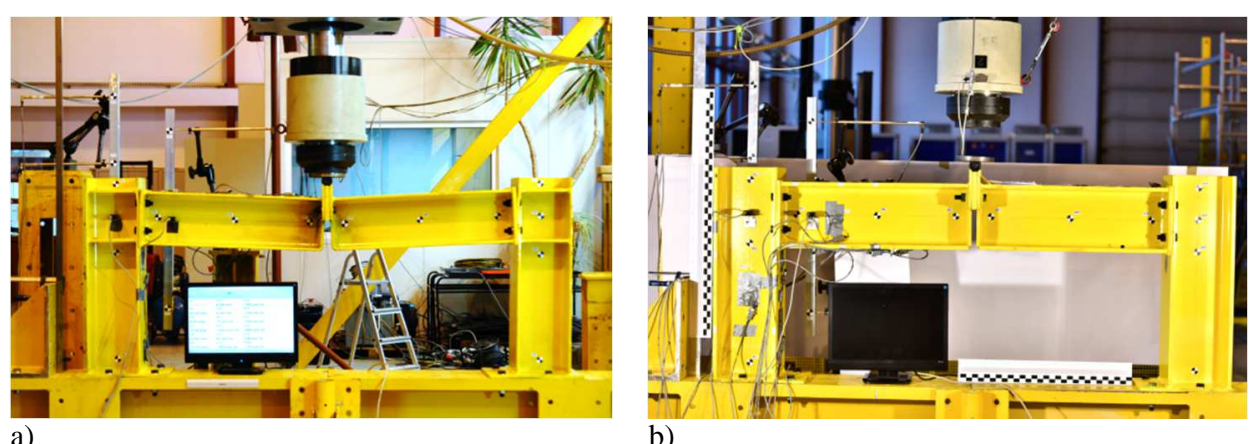

b)

Rys. 3. Stanowisko badawcze: a) Rama RH - HEA 240; b) Rama RB - HEB 260

Fig. 3. Research stand: a) Frame RH - HEA 240; b) Frame RB - HEB 260

W układzie ramowym RB wykonanym z kształtowników HEB 260 zastosowano również śruby klasy 10.9. Nieznacznie zmienił się osiowy rozstaw słupów $\left(L_{l}=1850 \mathrm{~mm}\right)$, w układzie tym zastosowano doczołowe połączenia rygla ze słupem w układzie bez żeber usztywniających w słupie, poziomy rozstaw śrub w połączeniu przyjęto wartości $w=150 \mathrm{~mm}$, odległości osi śrub od górnej półki rygla wynosi $c_{g l}=70 \mathrm{~mm}$. Profil rygla i słupa w tym układzie ramowym wykonano ze stali S355, blachy czołowe rygla oraz płyta podstawy słupa została wykonana ze stali S235. Układy ramowe w obydwu przypadkach zostały przymocowane do pomocniczej konstrukcji wsporczej trwale przytwierdzonej do podłogi siłowej. Połączenie słupów do belki pomocniczej przy użyciu czterech śrub M20 spowo- 
dowało odpowiednio sztywne zamocowanie, co w konsekwencji wykluczyło konieczność zastosowania bocznych elementów usztywniających układ ramowy.

\section{Opis wykonanych pomiarów}

Układ pomiarowy służący do wyznaczenia kąta obrotu węzła składał się z dwóch inklinometrów (Ln1, Ln2) oraz czterech czujników przemieszczeń (CP1, CP2, CP3, CP4). Schemat rozmieszczenia aparatury pomiarowej przedstawiono na rys. 4. Inklinometr zamocowany do środnika słupa oznaczono symbolem Ln1. Inklinometr zamocowany do środnika rygla oznaczono symbolem Ln2. Czujniki przemieszczeń

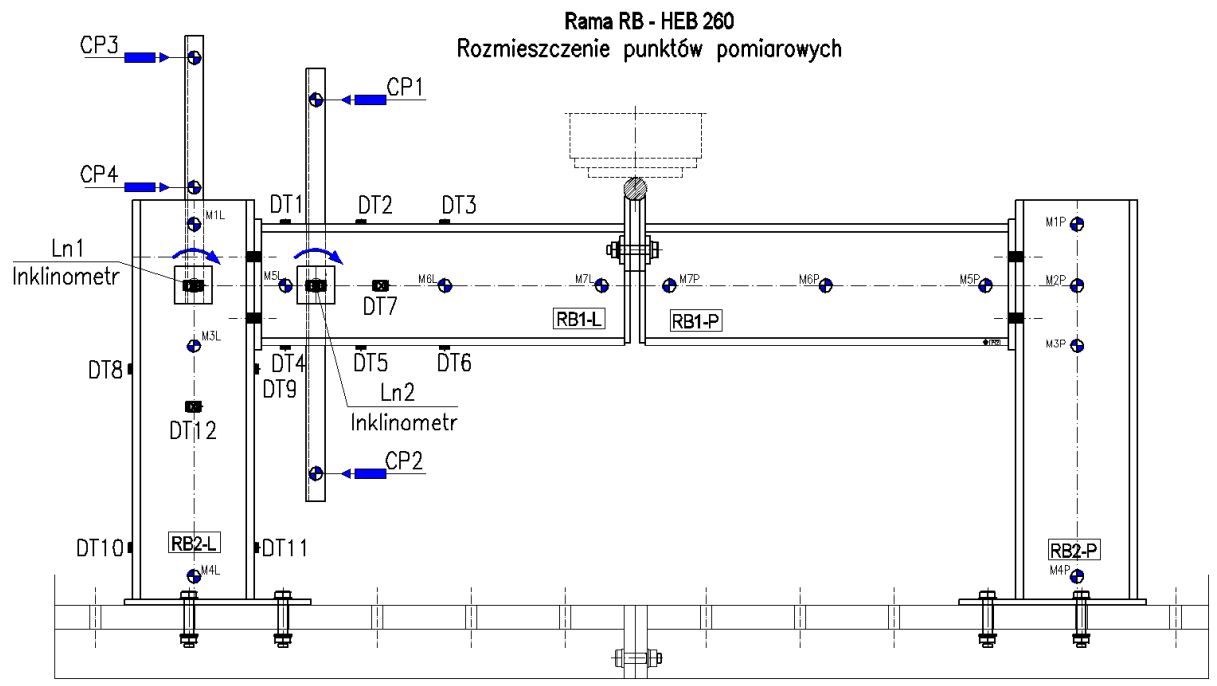

Rys. 4. Rozmieszczenie punktów pomiarowych dla ramy RB - HEB 260 (Ln - inklinometry, $\mathrm{CP}$ - czujniki przemieszczeń, DT - tensometry elektrooporowe, M - markery)

Fig. 4. Location of measurement points for the frame RB - HEB 260 ( $\mathrm{Ln}$ - inclinometers, $\mathrm{CP}$ - displacement sensors, DT - electro winning strain gauges, $\mathrm{M}$ - markers)

Wartość kąta obrotu węzła $\phi$ wyznacza się, jako różnicę kąta obrotu rygla $\phi_{\text {beam }}$ i kąta obrotu słupa $\phi_{\text {culumn }}$, co zapisano równaniem (3).

$$
\phi=\phi_{\text {beam }}-\phi_{\text {column }}
$$

gdzie: $\phi_{\text {beam }}$ - kąt obrotu rygla, $\phi_{c o l u m n}$ - kąt obrotu słupa.

W czwartym etapie walidacji poza wykonaniem standardowego pomiaru inklinometrami, tensometrami oraz czujnikami przemieszczeń, dokonano pomiaru kąta obrotu węzła metodą cyfrowej korelacji obrazu. Metoda ta polega na analizie zdjęć dużej rozdzielczości wykonanych za pomocą aparatu fotograficz- 
nego. Zdjęcia wykonane w określonych fazach obciążenia rejestrują stan deformacji poszczególnych składników węzła. Analizę odkształceń poszczególnych elementów węzła dokonuje się na podstawie analizy przemieszczeń punktów, które zostały oznaczone na badanym obiekcie za pomocą markerów. Na rys. 4. przedstawiono schemat rozmieszczenia tych punktów pomiarowych. W rozpatrywanym przypadku pomiar kąta obrotu został przeprowadzony osobno dla rygla i osobno dla słupa. Elementy układu pomiarowego kąta obrotu rygla oraz kąta obrotu słupa zostały zamocowane w obydwu układach ramowych do środnika kształtownika. Takie usytuowanie układu pomiarowego zapewnia dokonanie pomiaru średniego $\mathrm{w}$ środku kształtownika, co jest zgodne $\mathrm{z}$ pomiarem wykonywanym za pomocą inklinometrów.
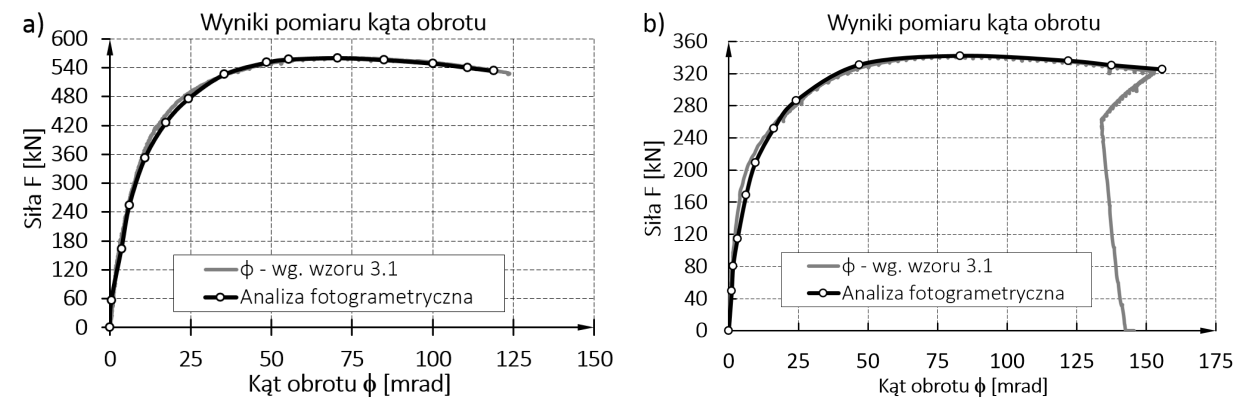

Rys. 5. Porównanie wyników pomiarów kąta obrotu metodą cyfrowej korelacji obrazu z wynikami pomiaru kąta inklinometrami: a) rama RB (HEB 260); b) rama RH (HEA 240)

Fig. 5. Results comparison of rotation angle measurement of digital image correlation method with the results of the inclinometer angle measurement: a) Frame RB (HEB 260); b) Frame RH (HEA 240)

Na rysunku rys. 5. przedstawiono wyniki pomiaru kąta obrotu węzła $\phi$ przy narastającym obciążeniu $F$ (rys. 5a - rama RB, rys. 5b- rama RH) przy użyciu inklinometrów oraz wyniki porównawcze pomiaru kąta obrotu przy zastosowaniu cyfrowej korelacji obrazu. Widać zbieżność wyników obu metod.

\section{Walidacja modelu MES}

W analizie MES modelu układu ramowego poddanemu badaniu przyjęto sprężysto-plastyczny model materiałowy uzyskany w wyniku realizacji pierwszego etapu walidacji [7]. Na rys. 6., linią ciągłą, przedstawiono charakterystyki materiałowe true strain-true stress wprowadzone do programu Ansys. W celu zwiększenia efektywności obliczeń wykonano model połowy układu ramowego, wykorzystując symetrię względem płaszczyzny środkowej układu. 

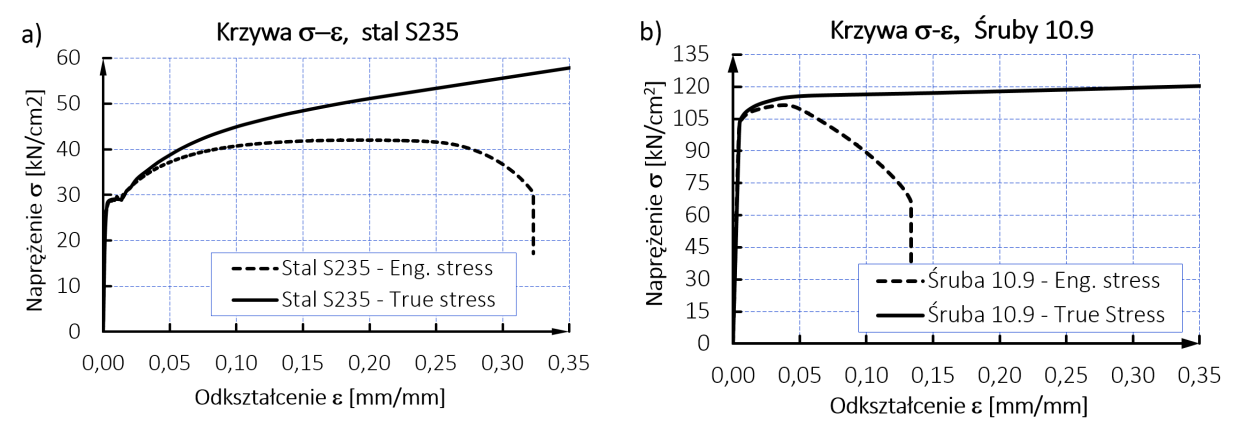

Rys. 6. Charakterystyka materiałowa: a) stal S235; b) śruba klasy 10.9 (ISO 4014)

Fig. 6. Material characteristic: a) steel S235; b) bolt grade 10.9 (ISO 4014)

Dla wszystkich elementów składowych węzła użyto trójwymiarowych elementów skończonych, typu Hex8, Tet4, Wed6 oraz Pyr5. Dla blachy czołowej oraz półki słupa przyjęto 5 warstw elementów skończonych. Powierzchnie kontaktowe pomiędzy poszczególnymi elementami węzła zamodelowano, jako nieliniowe z współczynnikiem tarcia przyjętym jak dla powierzchni w stanie naturalnym o wartości $\mu=0,2$. Sposób modelowania powierzchni kontaktowych pomiędzy poszczególnymi elementami składowymi układu ramowego, wykonanie modelu śruby oraz sposób siatkowania przyjęto analogicznie jak w pracach [7], [8], [9].

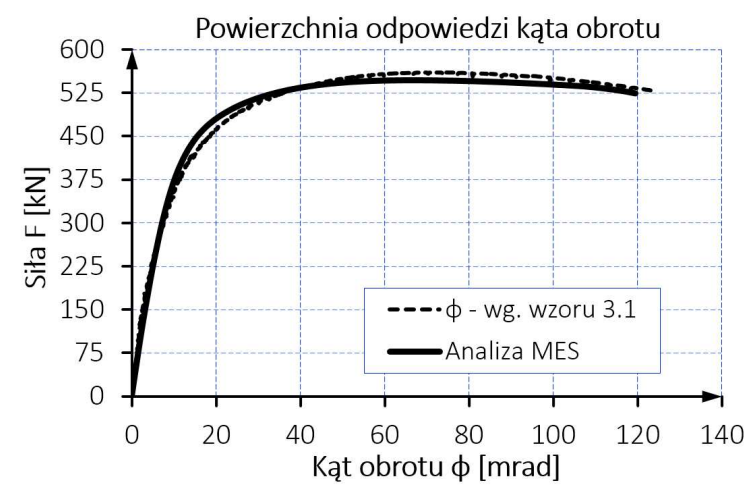

Rys. 7. IV Etap walidacji - porównanie wyników kąta obrotu (pomiar przy użyciu inklinometrów)

Fig. 7. IV Stage of validation - results comparison of rotation angle (measurement using an inclinometer)

Na rys. 7. przedstawiono porównanie wyników analizy MES z wynikami badań laboratoryjnych. Jako punkt odniesienia przyjęto kryterium porównawcze charakterystyk $F-\phi$. Wartość kąta obrotu $\phi$ wyznaczono przy użyciu wzoru (3). Widać dobrą zgodność przebiegu krzywych, co świadczy o adekwatności modelu MES. 
Na rysunku 8. pokazano obraz deformacji węzła ramy RB, otrzymany podczas badań doświadczalnych oraz w modelu MES przy obciążeniu $F=555,9 \mathrm{kN}$ $(\phi=55,34 \mathrm{mrad})$. Widać podobne formy deformacji, co potwierdza pozytywny wynik walidacji. W badanym układzie bez żeber usztywniających obserwuje się wyboczenie środnika słupa w obszarze docisku dolnej półki rygla, co w modelu MES uwidocznione jest w postaci koncentracji naprężeń.

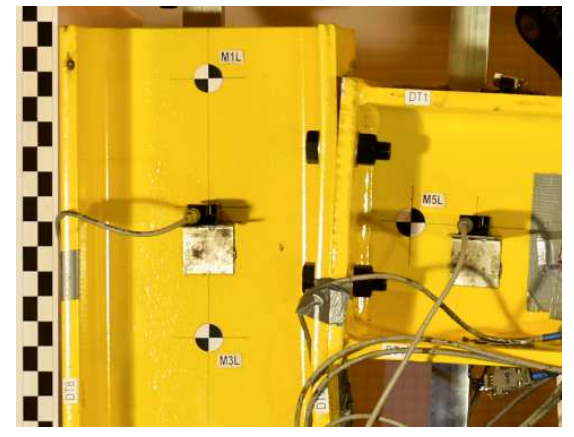

a)

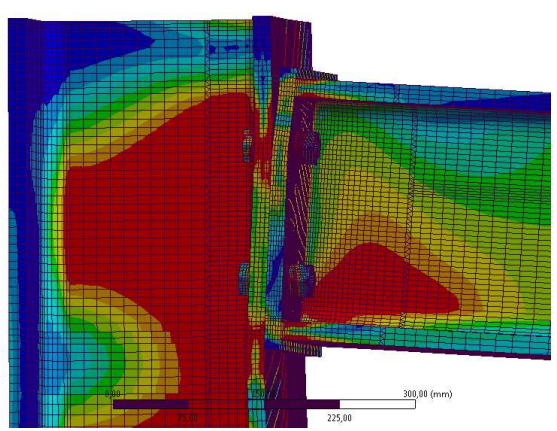

b)

Rys. 8. IV Etap walidacji - porównanie deformacji węzła $(F=555,9 \mathrm{kN}, \phi=55,34 \mathrm{mrad})$ : a) test laboratoryjny; b) analiza MES

Fig. 8. IV Stage of validation - comparison of joint deformation $(F=555,9 \mathrm{kN}, \phi=55,34 \mathrm{mrad})$ : a) laboratory test; b) FEM analysis

\section{Wnioski}

Przeprowadzenie wieloetapowej walidacji hierarchicznej jest warunkiem koniecznym otrzymania wiarygodnych wyników analizy MES badanych obiektów. Szczególnie jest to istotne w odniesieniu do konstrukcji i jej części poddanych dużym deformacjom. Wprowadzenie charakterystyk materiałowych, będących wynikiem procesu dostrajania modeli MES zrealizowanych w ramach walidacji pozwala analizować zachowanie się węzłów poddanych znacznym odkształceniom, bliskim stanu wyczerpania zdolności konstrukcji do przenoszenia obciążenia. Przedstawione $\mathrm{w}$ pracy wyniki IV etapu walidacji w pełni potwierdzają wiarygodność wyników tego etapu, jak i etapów wcześniejszych. Tak otrzymany model MES będzie wykorzystany do analizy zdolności do obrotu śrubowych węzłów doczołowych o różnej konfiguracji, w eksperymencie „numerycznym" zastępującym badania doświadczalne. Ostatecznym celem tych badań jest przygotowanie propozycji ilościowego oszacowania osiągalnej zdolności do obrotu węzłów, jako trzeciej, po nośności i sztywności, charakterystyki węzłów podatnych, wykorzystywanej w obliczeniach ramowych układów nośnych. 


\title{
Literatura
}

[1] Díaz C., Martí P., M. Victoria, and O. M. Querin,.: Review on the modelling of joint behavior in steel frames, Journal of Constructional Steel Research 67: pp. 741-758, 2011.

[2] Faella C., PilusoV., Rizzano G.: Structural steel semi rigid connections: Theory, design and software. CRC Press, Boca Raton, 2000.

[3] Girao A. M., Silva L., Bijlaard F.: Finite-Element Modeling of the Nonlinear Behavior of Bolted T-Stubs Connections, Journal of Structural Engineering, 132: pp. 918-928, 2006.

[4] PN-EN 1993-1-8, Eurokod 3: Projektowanie konstrukcji stalowych. Część 1-8: Projektowanie węzłów, PKN, 2006.

[5] Schwer L.E., Verification and validation in computational solid mechanics and the ASME Standards Committee. WIT Transactions on the Built Environment, Vol 84, 2005.

[6] PN-EN 1993-1-5, Eurokod 3: Projektowanie konstrukcji stalowych. Część 1-5: Blachownice, PKN, 2008.

[7] Ostrowski K., Kozłowski A., Walidacja hierarchiczna modeli MES. XIV Międzynarodowa Konferencja Naukowa Rzeszowsko - Lwowsko - Koszycka, Rzeszów, 2015.

[8] Ostrowski K., Kozłowski A., Analiza czynnikowa zdolności do obrotu użebrowanego połączenia doczołowego belki do słupa. Budownictwo i Architektura, Vol. 13(3) 2014, Lublin, 2014.

[9] Ostrowski K.: Finite element analysis of the rotation capacity of beam-to-column endplate bolted joints, Eurosteel 2014, $7^{\text {th }}$ European Conference on Steel and Composite Structures, pp. 315-316, September 10-12, Naples, 2014.

\section{EXPERIMENTAL STUDY OF THE PORTAL FRAME FOR THE VALIDATION OF FEM MODEL OF BEAM TO COLUMN JOINT}

\begin{abstract}
S u m m a r y
The laboratory test results of $4^{\text {th }}$ stage hierarchical validation of FEM model created for analysis of steel joint's rotation capacity have been presented in the paper. The research program contains performing laboratory tests of two portal frame made of hot rolled profiles and comparison of tests results with results obtained in numerical analysis using FEM by ANSYS software. As a comparative criterion was assumed the response curve of beam to column joint's rotation angle, which was determined in laboratory test by set of inclinometers. An assessment was done for the impact of ribbing the column for joint rotation capacity. Frame system without stiffening ribs was made of HEB260, while the system with stiffening ribs was made of HEA240. The components of frame systems were made of steel grade S235 and S355. As fixing elements have been used high strength bolts class 10.9 according to ISO 4014 .
\end{abstract}

Keywords: rotation capacity, FEM analysis, hierarchical validation, portal frame, beam to column joint, portal frame, beam to column joint 